\title{
Myocardial bridging over the left anterior descending: Myotomy, bypass, or both?
}

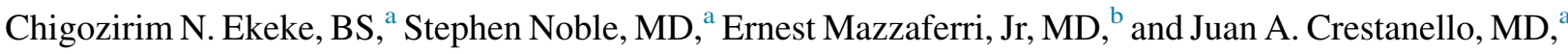 \\ Columbus, Ohio
}

Myocardial bridging of the left anterior descending (LAD) coronary artery occurs in $1 \%$ to $4.5 \%$ of coronary angiographies. ${ }^{1}$ Although the majority of the patients are asymptomatic, a small percentage will require surgery. ${ }^{2}$ Surgery for symptomatic myocardial bridge of the LAD may include myotomy, coronary artery bypass surgery, or both., ${ }^{2,3}$ Procedure selection is based on the size of the underlying artery during diastole, the presence of concomitant proximal coronary artery disease, and the presence of anatomic factors that would increase the risk of myotomy. We present 2 patients with myocardial bridges of the LAD, 1 treated with myotomy and 1 treated with both myotomy and bypass surgery.

\section{CASE 1}

The first patient was a 38-year-old man who had severe angina elicited by exercise and at rest. His symptoms

\footnotetext{
From the Divisions of Cardiac Surgery ${ }^{\mathrm{a}}$ and Cardiovascular Medicine, ${ }^{\mathrm{b}}$ The Heart and Vascular Center, The Ross Heart Hospital, Wexner Medical Center, The Ohio State University, Columbus, Ohio.

Disclosures: Authors have nothing to disclose with regard to commercial support. Received for publication Dec 9, 2014; accepted for publication Dec 22, 2014; available ahead of print Jan 31, 2015.

Address for reprints: Juan A. Crestanello, MD, N-816 Doan Hall, 410 West 10th Ave, Columbus, OH 43210 (E-mail: juan.crestanello@ osumc.edu).

J Thorac Cardiovasc Surg 2015;149:e57-8

$0022-5223 / \$ 36.00$

Copyright (C) 2015 by The American Association for Thoracic Surgery http://dx.doi.org/10.1016/j.jtcvs.2014.12.054
}

severely compromised his quality of life. His coronary angiogram demonstrated compression of a long segment of the LAD coronary artery during systole that completely disappeared during diastole (Figure 1, A). After medical therapy failed, myotomy of the bridging segment was performed (Figure 1, $B$ ). Because the arterial caliber of the intramyocardial and epicardial segments were similar, only myotomy was performed. His symptoms completely resolved.

\section{CASE 2}

The second patient was a 42-year-old man who presented with angina during exercise. Coronary angiogram showed compression of a long segment of the LAD during systole that persisted during diastole (Figure 2, A). Myocardial bridging was performed. Surgical correction involved myotomy of the bridging segment (Figure 2, B). Because the caliber of the intramyocardial segment was smaller than the distal artery, a coronary bypass with the left internal thoracic artery to the distal LAD was also performed (Figure 2, B). His symptoms of angina resolved.

\section{DISCUSSION}

The treatment of myocardial LAD bridging is challenging. Patients are usually young and may present with severe, usually atypical, symptoms often attributed to other causes. ${ }^{2}$ Once the diagnosis is made, medical management
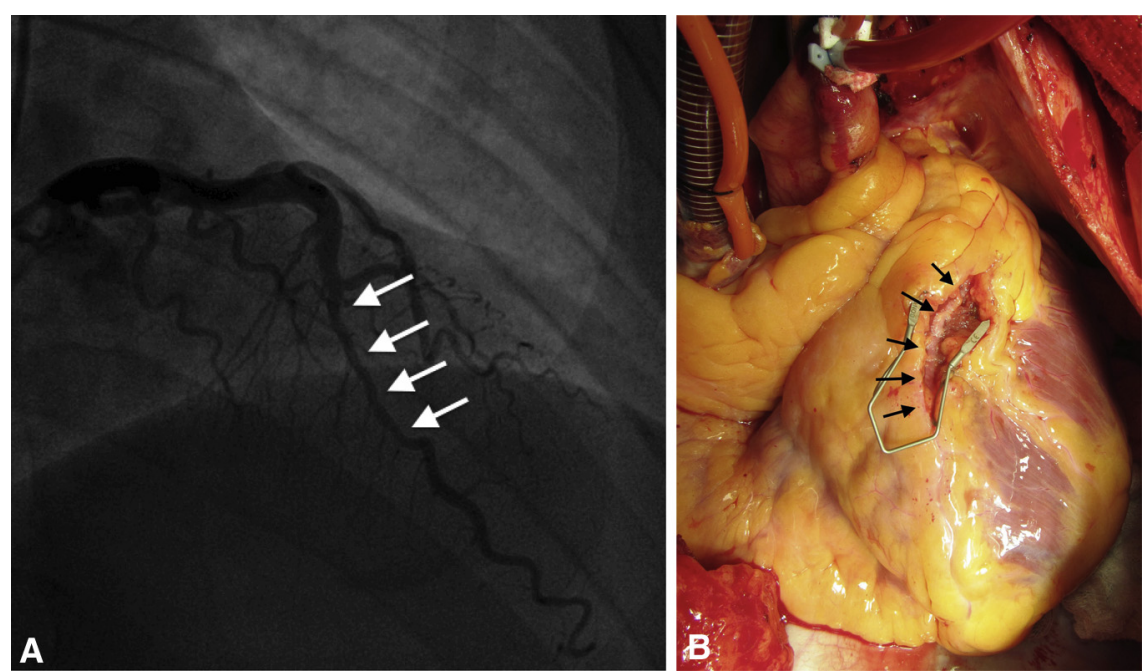

FIGURE 1. Case 1. A, Angiography demonstrates compression of the LAD coronary artery during systole (arrows). B, Operative picture demonstrating myotomy over the LAD. 

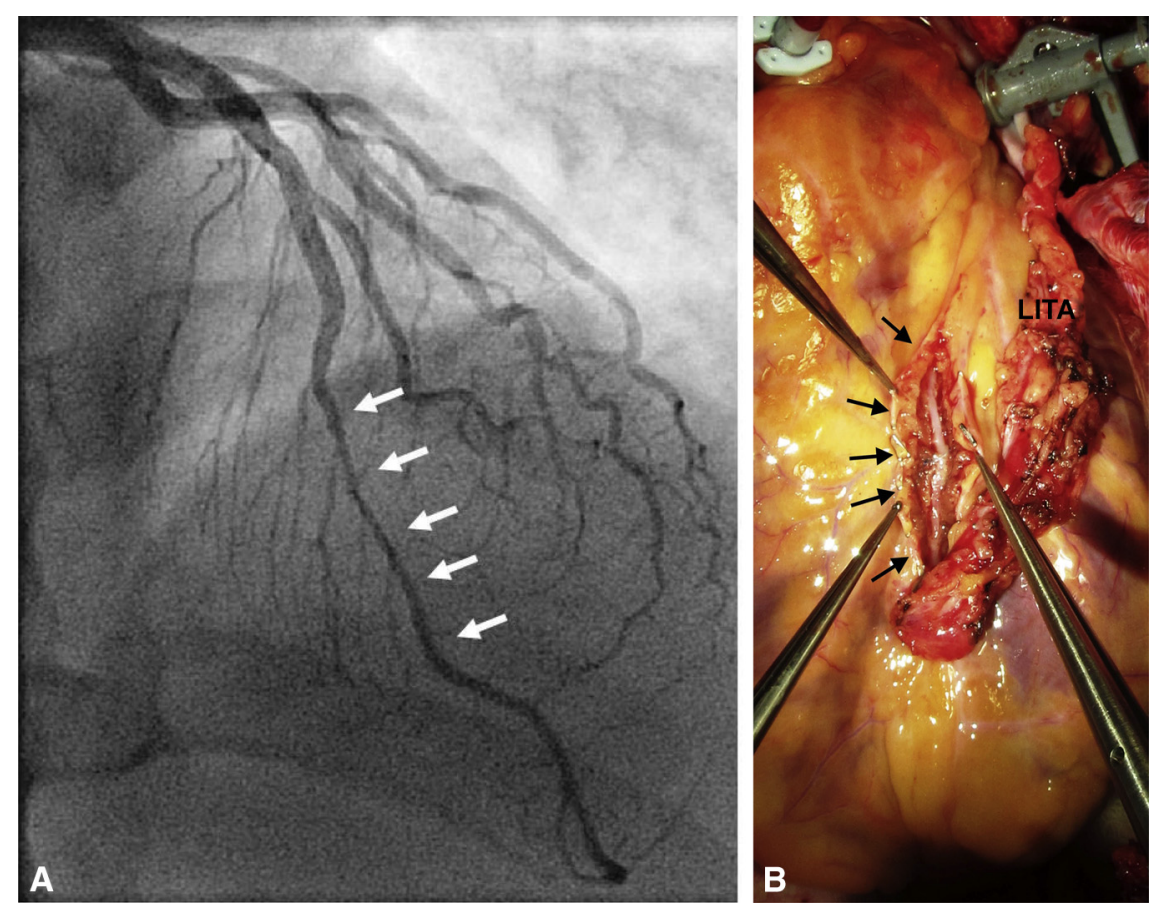

FIGURE 2. Case 2. A, Coronary angiogram showing long segment bridging of the LAD (arrows). Because this persisted during systole, treatment comprised myotomy (B, arrows) and bypass to the LAD with the left internal thoracic artery (B). LITA, Left internal thoracic artery.

should be attempted first. If this fails, surgery is recommended. The options for the surgical management of myocardial bridge over the LAD include myotomy, bypass surgery, or both. ${ }^{2,3}$

Myotomy involves the division of the muscle fibers over the LAD coronary artery using a surgical blade. The artery is identified distal to the bridge on its epicardial portion and is followed proximally with division of the muscle fibers over the artery. The proximal and distal end of the bridge should be identified and the artery freed by at least $1 \mathrm{~cm}$ proximally and distally. For optimal results, this procedure should be performed under cardiopulmonary bypass with an arrested heart. The immobile bloodless field ensures optimal results and minimizes the chances of complications. Complications associated with myotomy include injury to the artery, incomplete myotomy, and right ventriculotomy. To avoid right ventriculotomy, the myotomy should be located anterior toward the left side of the artery. Long-term complications may include scarring of the myotomy over the artery with recurrence of the compression. Scarring may occur especially in deep bridges. Ventricular aneurysms also have been described. ${ }^{2}$

Bypass surgery can be performed in combination with or instead of myotomy. Isolated myotomy is sufficient when the underlying coronary artery is normal in size and has no proximal atherosclerotic lesions. This was the case in our first patient. If the caliber of the LAD during diastole is smaller than the proximal nonbridging segment or there is concomitant coronary artery disease, bypass surgery to the artery distal to the bridge is recommended. Bypass also is recommended when there is a high risk of scarring after myotomy or if there are technical considerations that preclude myotomy. For example, tortuous arteries may pose an increased risk of right ventriculotomy. The left internal thoracic artery is the conduit of choice for bypass. Compromised long-term bypass patency secondary to competitive flow may be a concern when bypass and myotomy are performed in the absence of proximal coronary obstruction.

\section{CONCLUSIONS}

The surgical strategy for the management of patients with myocardial bridges should be customized. The treatment of choice is myotomy. Bypass surgery can be added when there is proximal coronary obstruction or anatomic anomalies that increase the risk of recurrence of the obstruction.

\section{References}

1. Bourassa MG, Butnaru A, Lespérance J, Tardif JC. Symptomatic myocardial bridges: overview of ischemic mechanisms and current diagnostic and treatment strategies. J Am Coll Cardiol. 2003;41:351-9.

2. Bruschke AV, Veltman CE, de Graaf MA, Vliegen HW. Myocardial bridging: what have we learned in the past and will new diagnostic modalities provide new insights? Neth Heart J. 2013;21:6-13.

3. Sun X, Chen H, Xia L, Zhao D, Ding W, Wang C. Coronary artery bypass grafting for myocardial bridges of the left anterior descending artery. J Card Surg. 2012;27: 405-7. 